\title{
Kv1 channels regulate variations in spike patterning and temporal reliability in the avian cochlear nucleus angularis
}

\author{
Authors: \\ James F. Baldassano \\ Katrina M. MacLeod
}

Affiliation:

Department of Biology

University of Maryland, College Park

College Park, MD 20742

Running head: Kv1 regulation of spiking in nucleus angularis

\section{Corresponding author:}

Katrina MacLeod

Department of Biology

University of Maryland

College Park, MD 20742

(301) 405-7174 (phone)

(301) 314-9358 (fax)

macleod@umd.edu

Keywords: Action potential; Spike initiation; potassium channel; chick; coincidence detection 
bioRxiv preprint doi: https://doi.org/10.1101/2021.10.08.463546; this version posted October 9, 2021. The copyright holder for this preprint (which was not certified by peer review) is the author/funder, who has granted bioRxiv a license to display the preprint in perpetuity. It is made available under aCC-BY-NC 4.0 International license. 


\section{Abstract}

Diverse physiological phenotypes in a neuronal population can broaden the range of computational capabilities within a brain region. The avian cochlear nucleus angularis (NA) contains a

4 heterogeneous population of neurons whose variation in intrinsic properties results in

5 electrophysiological phenotypes with a range of sensitivities to temporally modulated input. The low-

6 threshold potassium conductance $\left(G_{K L T}\right)$ is a key feature of neurons involved in fine temporal structure

7 coding for sound localization but a role for these channels in intensity or spectrotemporal coding has not

8 been established. To determine whether $\mathrm{G}_{\mathrm{KLT}}$ affects the phenotypical variation and temporal properties

9 of NA neurons, we applied dendrotoxin (DTX), a potent antagonist of Kv1-type potassium channels, to

10 chick brain stem slices in vitro during whole-cell patch clamp recordings. We found a cell-type specific

11 subset of NA neurons were sensitive to DTX: single-spiking NA neurons were most profoundly affected,

12 as well as a subset of tonic firing neurons. Both tonic I (phasic onset bursting) and tonic II (delayed

13 firing) neurons showed DTX sensitivity in their firing rate and phenotypical firing pattern. Tonic III

14 neurons were unaffected. Spike time reliability and fluctuation sensitivity measured in DTX-sensitive NA

15 neurons was also reduced with DTX. Finally, DTX reduced spike threshold adaptation in these neurons,

16 suggesting that $\mathrm{G}_{\mathrm{KLT}}$ contributes to the temporal properties that allow coding of rapid changes in the

17 inputs to NA neurons. These results suggest that variation in Kv1 channel expression may be a key factor

18 in functional diversity in the avian cochlear nucleus.

\section{New and noteworthy}

The dendrotoxin-sensitive voltage-gated potassium conductance typically associated with

23 neuronal coincidence detection the timing pathway for sound localization is demonstrated to affect 
bioRxiv preprint doi: https://doi.org/10.1101/2021.10.08.463546; this version posted October 9, 2021. The copyright holder for this preprint

(which was not certified by peer review) is the author/funder, who has granted bioRxiv a license to display the preprint in perpetuity. It is made available under aCC-BY-NC 4.0 International license.

24 spiking patterns and temporal input sensitivity in the intensity pathway in the avian auditory brain stem.

25 The Kv1-family channels appear to be present in a subset of cochlear nucleus angularis neurons,

26 regulate spike threshold dynamics underlying high-pass membrane filtering, and contribute to intrinsic

27 firing diversity.

28

29 


\section{Introduction}

Neurons in early sensory nuclei must process a wealth of incoming information to extract

features that are relevant to their particular circuit. The avian cochlear nucleus is composed of two divisions, nucleus magnocellularis (NM) and nucleus angularis (NA), each of which extract unique

34 information from auditory nerve activity in parallel (1). NM neurons encode timing information by

35 phase-locking to the fine structure in the acoustic signal $(2,3)$, partly enabled by specialized intrinsic

36 properties such as a large low threshold voltage-gated potassium conductance $\left(\mathrm{G}_{\mathrm{KLT}}\right)(4-8)$. This

37 dendrotoxin (DTX)-sensitive conductance is attributed to the expression of the Kv1 family of potassium

38 channels, particularly Kv1.1 and Kv1.2, that are prominent throughout the auditory brainstem of birds

39 and mammals (9-15).

In contrast to NM, NA is classically understood to process information about sound intensity or

41 level in service of interaural level difference computation. (3, 16-18) More broadly, however, NA

42 neurons are also involved in spectrotemporal and amplitude modulation coding and auditory envelope

43 processing. $(19,20)$ The neuronal population in NA shows greater morphological and physiological

44 heterogeneity than those in NM and NL $(1,21,22)$. Sound-evoked responses observed in vivo in NA fall

45 into a range of response categories, such as onset, chopper, primary-like, and "Type IV", similar to

46 corresponding recorded responses in the mammalian cochlear nucleus $(2,23,24)$. Likewise, NA neurons

47 display a range of electrophysiological phenotypes that likely arise from the expression of a more

48 diverse array of ion channels (22, 25-29). Single spiking neurons in NA most closely resemble NM

49 neurons, while a broad group of repetitively firing neurons in NA can be further subdivided according to

50 their firing patterns to step currents in vitro: early burst firing (tonic I), late or delayed firing (tonic II) and

51 regular spiking (tonic III) $(25,26)$. A DTX-sensitive conductance has been shown to be required for the

52 single-spiking phenotype, but blocking this conductance also elevated firing rates in tonic neurons (22). 
53 Along with immunohistochemical evidence for Kv1 channel protein expression in NA (10, 30), these data

54 suggest that $\mathrm{G}_{\mathrm{KLT}}$ is present and active in shaping NA neuron physiology. The ion channel basis of the

55 different tonic phenotypes is not yet known.

The parallels between the heterogeneity among in vivo response types and the heterogeneity

57 among in vitro response types suggests that intrinsic properties may have a significant effect on the

58 transformation of auditory information. We have recently investigated type-specific variation in

59 sensitivity to temporally modulated stimuli in the tonic neurons in vitro and shown how diversity in

60 intrinsic properties can enhance stimulus encoding $(26,27)$. Temporal modulation sensitivity in vitro and

61 bandpass feature extraction in vivo could be replicated in NA neurons using a phenomenological model

62 of adaptive spike thresholds $(19,28)$. While the model was originally derived from the biophysical

63 phenomenon of sodium channel inactivation (31), its ion channel basis in NA has not been empirically

64 confirmed and could also be influenced by other subthreshold conductances, including $\mathrm{G}_{\mathrm{KLT}}$ (32-34).

66 block $G_{\text {KLT }}$ and test whether $G_{\text {KLT }}$ was needed to elicit the various spiking phenotypes among the tonic

67 neurons. We further investigated whether $\mathrm{G}_{\mathrm{KLT}}$ was necessary for the temporal reliability of firing, high-

68 pass filtering properties, and spike threshold adaptation that characterized a subset of tonic firing

69 neurons.

70 Introduction Word count- 552

71

72 


\section{Methods \& Materials}

\section{Brain slice preparation}

All animal procedures were performed with Institutional Animal Care and Use Committee

76 approval and according to University of Maryland guidelines on animal welfare. Chicken (Gallus gallus)

77 embryos incubated to embryonic day 17-18 were cooled and rapidly decapitated, and the head section

78 containing the brain stem blocked, placed in a chilled, oxygenated low-sodium artificial cerebrospinal

79 fluid (ACSF)(low-Na+ ACSF in mM: $97.5 \mathrm{NaCl}, 3 \mathrm{KCl}, 2.5 \mathrm{MgCl}_{2}, 26 \mathrm{NaHCO}_{3}, 2 \mathrm{CaCl}_{2}, 1.25 \mathrm{NaH}_{2} \mathrm{PO}_{4}, 10$

80 dextrose, 3 HEPES, and 230 sucrose) and dissected out of the cranium. The brain stem tissue block was

81 mounted with cyanoacrylate glue and supported with $5 \%$ agarose gel solution. Transverse slices $(250 \mu \mathrm{m}$

82 thick) containing NA were cut on a vibrating tissue slicer (Leica Microsystems, Wetzler, Germany). Slices

83 were incubated in normal ACSF (in mM: $130 \mathrm{NaCl}, 3 \mathrm{KCl}, 2 \mathrm{MgCl}_{2}, 26 \mathrm{NaHCO}_{3}, 2 \mathrm{CaCl}_{2}, 1.25 \mathrm{NaH}_{2} \mathrm{PO}_{4}, 10$

84 dextrose, and $3 \mathrm{HEPES}$ ) at $34^{\circ} \mathrm{C}$ for $30 \mathrm{~min}$ then held at room temperature in normal ACSF until

85 recording.

Whole cell patch-clamp electrophysiology

Slices were placed in a recording chamber and continuously perfused with oxygenated, warmed normal ACSF ( $1-2 \mathrm{~mL} / \mathrm{min}, 28-30^{\circ} \mathrm{C}$ ) containing synaptic blockers ( $3 \mu \mathrm{M}$ strychnine, $20 \mu \mathrm{M}$ SR95531

89 (gabazine), $15 \mu \mathrm{M} \mathrm{DXQX}$, and $20 \mu \mathrm{M}$ AP5; Sigma) to isolate intrinsic activity. Whole cell patch-clamp

90 recordings were performed on visually identified NA cells using infrared differential interference

91 contrast video microscopy. Initial glass recording pipette resistances were 3-7 M 2 . Pipettes were filled

92 with a potassium gluconate intracellular recording solution (in $\mathrm{mM}: 110$ potassium gluconate, $20 \mathrm{KCl}, 1$

93 EGTA, $2 \mathrm{MgCl}_{2}, 10 \mathrm{HEPES}, 2 \mathrm{Na}_{2} \mathrm{ATP}, 0.3 \mathrm{Na}_{2} \mathrm{GTP}, 10$ phosphocreatine and $0.2 \%$ biocytin). Series

94 resistance, cell capacitance, and resting membrane voltage were measured upon break-in in voltage

95 clamp mode. Voltage recordings were made with a MultiClamp 700B amplifier (Molecular Devices, 
Sunnyvale, CA) set to current-clamp mode. Application of the current stimulus and recording of the

97 voltage output were controlled by an analog-to-digital board (National Instruments, Austin, TX) and a computer running custom software written in IGOR Pro (WaveMetrics, Lake Oswego, OR). A holding current was applied to maintain a constant voltage baseline of approximately $-60 \mathrm{mV}$. Drug application

100 for pharmacological manipulation of voltage response was performed by bath application (100 nM $\boldsymbol{\alpha}$ 101 dendrotoxin, Tocris-Cookson). 400-ms-duration flat current steps of varying amplitudes from -150 pA up to $750 \mathrm{pA}$ in 50 or $100 \mathrm{pA}$ 104 intervals. We collected data from 77 NA neurons (20 single-spike, 12 tonic I, 16 tonic II, 23 tonic III, and 6 damped). The patterns of action potential (AP) firing over multiple current steps were used to divide NA neurons into 3 broad groups: single-spiking, tonic firing or damped. Single spiking NA neurons

107 resembled neurons in NM and NL, firing a single onset AP at all step amplitudes. Tonic firing neurons 108 fired repetitively with overshooting action potentials throughout the duration of the flat current steps at most amplitudes, but could be further subdivided based on their characteristic firing at depolarizing

110 steps just above rheobase: burst firing at the onset of current injection (tonic I), a delay followed by 111 burst firing (tonic II), or tonic firing with uniform interspike intervals (tonic III) (see (25) for more details).

112 Damped neurons fired broad APs that progressively declined in amplitude into oscillatory subthreshold

113 potentials. If the neuron type was ambiguous from the current levels utilized, subsequent, smaller

114 intervals were used to distinguish the phenotype. Passive membrane properties were assessed using a 115 small hyperpolarizing current step (-50 pA). 
duration). Stimuli to acquire noise $f$-I curves were constructed by convolving Gaussian white noise with

120 an exponential function (time constant, $3 \mathrm{~ms}$ ) added to a DC step function as described previously (26,

121 27). These noise stimuli simulate the arrival of many small, stochastic, and statistically independent

122 synaptic currents, both excitatory and inhibitory. To accommodate cell-to-cell differences in input

123 resistance, a standard noise current was created by calibrating the standard deviation (around a zero

124 mean) of the noise current to generate a $2-m V$ standard deviation in the membrane potential in the

125 target neuron, designated " $1 \sigma$ ". The amount of voltage fluctuation was varied by multiplying the

126 standard noise stimulus by a factor of 2,4 , or 8 (i.e. 4-, 8-and 16-mV voltage fluctuation, respectively).

127 Each trial had an interstimulus interval of 8-10 seconds. A hyperpolarizing conditioning pre-pulse (-50

$128 \mathrm{pA}, 1 \mathrm{sec}$ ) was applied prior to each stimulus to minimize sodium channel inactivation from the prior

129 stimulus. A complete series of stimuli in the parameter space [mean DC, noise level] was systematically

130 generated by varying the mean current amplitude and noise level independently (3 noise levels, 5-7 DC

131 levels). Firing rates were averaged across 3 stimulus repetitions over the full 2-second duration and

132 reported as mean \pm SD in Hertz. After acquisition of control data, DTX (100 nM) was bath-applied to the

133 slice and data for drug trials acquired after a 10 minute wash in period.

curves were devised. One metric quantified the total area difference index (ADI)(28):

$$
A D I=\frac{\sum_{i=1}^{n} \operatorname{norm} F R_{80, i}-\sum_{i=1}^{n} \operatorname{norm} F R_{2 \sigma, i}}{\sum_{i=1}^{n} \operatorname{norm} F R_{8 \sigma, i}}
$$




$$
\triangle M a x F R=\frac{\operatorname{MaxFR}_{8 \sigma}-\operatorname{Max} F R_{2 \sigma}}{\operatorname{MaxF}_{8 \sigma}}
$$

where MaxFR refers to the maximum firing rate value of each $f$-I curve. Both metrics varied from

1420 (curves are identical) to 1 (maximum difference). Plotting these points (MaxFR index and the ADI

143 index) against each other produced a spectrum of fluctuation sensitivity. Neurons closest to the origin

144 were more "integrator-like", while neurons further away from the origin were more "differentiator-

145 like". Using the criteria of $A D I$ and $\Delta$ MaxFR $>0.2$, we were able to test the noise $f$-I curves from 15

146 differentiators and 5 integrators with DTX. $\triangle$ MaxFR index and ADI index were statistically compared

147 using Wilcoxon's t-test.

Spike timing reliability

After noise was calibrated, a $4 \sigma$ noisy current was injected into neurons at a single DC current step amplitude (typically 150-400 pA) to produce a firing rate between $20-50 \mathrm{~Hz}$. Repeated trials of 2

151 second long frozen noisy current injections were injected (usually 30 to 45 trials, or until >600 spikes 152 were collected) before and after DTX application. To quantify neuronal reliability, we calculated a 153 shuffled autocorrelogram (SAC), a histogram of all interspike intervals between spikes across trials, 154 excluding intervals within the same trial. The SAC is normalized by the normalizing factor (NF):

$$
N F=N \cdot(N-1) \cdot r^{2} \Delta \tau D
$$

157 function ( $0.2 \mathrm{~ms})$ and $D$ is the length of the stimulus $(2 \mathrm{sec})(26,27,35,36)$. The SAC was fit with a

158 Gaussian function, whose central peak is defined as the correlation index $(\mathrm{Cl})$. The precision of the firing

159 between trials is represented in the full-width at half-maximum (FWHM) of the Gaussian curve, measured by 


$$
F W H M=2 \sqrt{2 \ln 2} \cdot \sigma_{S A C}
$$

FWHM, referred to as width, were quantified and compared using Wilcoxon's t-test.

165

166

\section{Mutual information}

To quantify the mutual information $(\mathrm{I})$ between spike trains under control conditions $(\mathrm{X})$ versus those recorded in DTX $(Y)$, spike times were binned $(1 \mathrm{~ms})$ and their time bin distributions $\left(\mathrm{x}_{\mathrm{i}}, \mathrm{y}_{\mathrm{i}}\right)$ were used to calculate Shannon's equation for mutual information $(37,38)$ :

$$
I(X ; Y)=H(X)-H(X \mid Y)
$$

where $H(X)$ is the marginal entropy, or the observable information of $X$ :

$$
H(X)=-\sum_{i=1}^{n} p\left(x_{i}\right) \log _{2} p\left(x_{i}\right)
$$

where $p\left(x_{i}\right)$ is the probability of distribution $x_{i}$ and the entropy is given in bits. $H(X \mid Y)$, the conditional entropy, is the reduction of uncertainty about $\mathrm{X}$ given $\mathrm{Y}$ :

$$
H(X \mid Y)=\sum_{i, j}^{n} p\left(x_{i}, y_{j}\right) \log _{2} \frac{p\left(x_{i}, y_{j}\right)}{p\left(y_{j}\right)}
$$

$$
M I=1-H(X \mid Y)
$$

Where $p\left(x_{i}, y_{i}\right)$ is the probability that $X=x_{i}$ and $Y=y_{i}$. To control for random changes or response drift over the recording time, the experimental mutual information was compared to the mutual entropy calculated between control and "sham" conditions, where ACSF without DTX was washed into the recording chamber. Mutual information is reported in bits but bounded by zero and 1, and then 
bioRxiv preprint doi: https://doi.org/10.1101/2021.10.08.463546; this version posted October 9, 2021. The copyright holder for this preprint

(which was not certified by peer review) is the author/funder, who has granted bioRxiv a license to display the preprint in perpetuity. It is made available under aCC-BY-NC 4.0 International license.

180 subtracted from 1 which allows for zero to mean $\mathrm{X}$ and $\mathrm{Y}$ are completely independent and 1 to mean $\mathrm{X}$ is

181 entirely predicted by $\mathrm{Y}$, analogous to a similarity measure.

182

The action potential threshold was defined as the voltage at which an all-or-none regenerative

185 spike was initiated. This threshold was determined by using the first derivative of the voltage as

186 previously described (19). A criterion value of the derivative was selected and applied for the entire set

187 of voltage responses across the $f-I$ curve. Neither small changes in the criterion value nor the alternative

188 of using the second derivative affected the results of within-subject analyses. Direct comparisons of

189 absolute threshold between neurons, however, were omitted, as differences in the criterion applied

190 could affect across-subject comparisons. The mean, median, and variance of the spike threshold

191 measured across the action potentials for a given stimulus were calculated for each DC step amplitude

$192 \mathrm{~m}$ and noise level s combination. The mean and median were nearly identical in all cases, as expected

193 for nearly normal distributions. 


\section{Results}

Spiking patterns in NA are shaped by a DTX-sensitive potassium conductance.

To determine whether low threshold potassium channel activation was involved in shaping the electrophysiological phenotypes observed in the chick cochlear nucleus NA, we recorded the voltage responses before and after bath application of DTX (100 nM), a specific antagonist of the Kv1.1 and

Kv1.2 channels. We characterized the firing patterns and passive membrane properties using a series of shown previously, in control conditions NA neurons displayed heterogeneous spiking phenotypes in

205 vitro that could be broadly classified as single spiking (Fig. 1Ai) or tonic firing (Fig. 1Bi-Di)(25-27) Using small current steps, tonic firing neurons can be further distinguished into 3 subgroups based on whether

207 they tend to show early bursts (tonic I, Fig. 1Bi), late bursts (tonic II, Fig. 1Ci), or repetitive firing evenly 208 spaced for the duration of the stimulus (tonic III, Fig. 1Di)(see also 25 ).

When DTX was applied, changes in the firing patterns were observed in single spiking, tonic I

210 and tonic II neurons. In all single spiking neurons, which characteristically fire single onset spikes upon

211 depolarization in control conditions, DTX application induced repetitive firing throughout the current

212 injection ( $\mathrm{n}=12$; Fig 1Aii), in agreement with a previous study (22). In tonic I neurons DTX application

213 eliminated the burst cessation in these neurons that occurred at low-amplitude steps in control and

214 instead induced firing throughout the step duration at all step levels, ( $n=9$, Fig 1Bii). Similarly, in tonic II

215 neurons DTX application eliminated the delay in firing at low-amplitude steps in control ( $n=8$, Fig. 1Cii).

216 Tonic 3 neurons, in contrast, showed no apparent changes in firing pattern ( $n=13$, Fig. 1Dii).

218 functions for tonic I and tonic II neurons, as well as single spiking neurons (single spiking: $n=12, p=0.04$ 
at step amplitude $0.05 \mathrm{nA}, \mathrm{P}<0.001$ at $0.15-0.35 \mathrm{nA}$, Fig. 1Aiii; tonic $1: \mathrm{n}=9, \mathrm{P}<0.001$ at $0.15-0.35 \mathrm{nA}$,

Fig. 1Biii; tonic 2:, $\mathrm{n}=8, \mathrm{P}<0.001$ at $0.15-0.35 \mathrm{nA}$, Fig1Ciii; Sidak's multiple comparisons test). These

firing rate changes were accompanied by a reduction in the threshold current amplitude (rheobase) (Fig.

1Aiv-Civ single spiking control mean $=0.29 \pm 0.09 \mathrm{nA}$, DTX mean $=0.13 \pm 0.08 \mathrm{nA}, \mathrm{P}=0.001$, tonic I

control mean $=0.21 \pm 0.07 \mathrm{nA}, \mathrm{DTX}$ mean $=0.78 \pm 0.4 \mathrm{nA}, \mathrm{P}=0.03$, tonic II control mean $=0.26 \pm 0.07 \mathrm{nA}$,

DTX mean $=0.14 \pm 0.8 \mathrm{nA}, \mathrm{P}=0.03$, Wilcoxon's test). These changes in excitability were likely partly due

to the increase in input resistance measured in these neurons (single-spike: $n=12$, control $R_{\text {in }}=101.6 \pm$

17.14 $\mathrm{M} \Omega($ mean $\pm S D)$, DTX Rin $=191.7 \pm 31.37 \mathrm{M} \Omega, P=0.001$, Fig. $1 \mathrm{Av}$; tonic $\mathrm{I}: \mathrm{n}=9$, control $\mathrm{R}_{\text {in }}=$

$243.7 \pm 29.69 \mathrm{M} \Omega, \mathrm{DTX} R_{\text {in }}=277.8 \pm 36.93, P=0.039$, Fig. $1 \mathrm{Bv}$; tonic II: $n=8$, control $R_{\text {in }}=230.6 \pm 29.72$

$M \Omega, D T X R_{\text {in }}=265.5 \pm 38.1 M \Omega, P=0.042$, Fig. $\left.1 C v\right)$. In contrast, tonic III neurons showed no effects of

DTX application on their firing rate, input output function or rheobase (Fig. 1Di-iv tonic III control mean rheobase $=0.11 \pm 0.06 \mathrm{nA}$, DTX mean rheobase $=0.10 \pm 0.08 \mathrm{nA}, \mathrm{P}>0.99)$ nor in their input resistance $(\mathrm{n}$ $=13$, Fig. $1 D v$, control $R_{\text {in }}=289.7 \pm 26.2 M \Omega$, DTX $R_{\text {in }}=291.0 \pm 24.9 M \Omega, P=0.47$, Fig. 1Div). Finally, a

232 separate subset of NA neurons were characterized in control conditions as having a 'damping'

233 phenotype: broader action potentials that diminished in amplitude and whose voltage oscillates around

234 a membrane voltage. In these neurons, DTX application had no apparent effect on the voltage response

235 (Fig. 2A). Neither the damping constant (Fig. 2B) nor the input resistance (Fig. 2C) were altered.

236 Together, these results indicate that a DTX-sensitive conductance, the putative $\mathrm{G}_{\mathrm{LKT}}$ conductance,

237 contributes to the spiking patterns and firing rates of a specific subset of NA neurons.

The DTX-sensitive conductance improves temporal firing reliability and information content in tonic firing

239 neurons 

control $\mathrm{Cl}=28.9 \pm 6.7, \mathrm{DTX} \mathrm{Cl}=11.1 \pm 5.4, \mathrm{n}=9, \mathrm{P}=0.0059$; tonic II: control $\mathrm{Cl}=13.7 \pm 4.6, \mathrm{DTX} \mathrm{Cl}=7.0$ spiking: control FWHM $=0.5 \pm 0.34 \mathrm{~ms}$, DTX FWHM $=1.2 \pm 1.0 \mathrm{~ms}, \mathrm{P}<0.001$; tonic I: control FWHM $=$

$$
2.02 \pm 0.93 \mathrm{~ms}, \mathrm{DTX} F W H M=3.11 \pm 1.22 \mathrm{~ms}, \mathrm{P}<0.001 \text {; tonic II: control FWHM }=1.97 \pm 0.32 \mathrm{~ms}, \mathrm{DTX}
$$

FWHM $=3.41 \pm 0.71 \mathrm{~ms}, \mathrm{P}=0.039$, Fig. $4 \mathrm{C}$ ). In contrast, in tonic III or damped neurons, DTX application had no significant effect on the SAC peak (tonic III: $\mathrm{Cl}=4.83 \pm 3.82, \mathrm{DTX} \mathrm{Cl}=4.68 \pm 3.98, \mathrm{n}=12, \mathrm{P}=0.84$; damped: control $\mathrm{Cl}=3.59 \pm 1.04, \mathrm{DTX} \mathrm{Cl}=4.96 \pm 2.88, \mathrm{n}=9, \mathrm{P}=0.84$ ) or width (tonic III: $\mathrm{FWHM}=3.85 \pm$ $1.64 \mathrm{~ms}$, DTX FWHM $=4.32 \pm 2.13 \mathrm{~ms}, \mathrm{P}=0.41$; damped: control FWHM $=6.43 \pm 3.14 \mathrm{~ms}$, DTX FWHM = same subset of cell types that showed firing rate changes with DTX (single spiking, tonic I and II) but not

259 in the tonic III or damped neurons.

262 (see Methods )(37, 38). MI quantifies the predictive value of one data set toward the other in bits,

263 where 1 indicates complete certainty and zero indicates complete independence between the data sets.

264 The MI between control and DTX trials was low in single-spike, tonic I, and tonic II neurons (Fig. 5, red 265 markers and bars), indicating a high degree of dissimilarity. The same analysis applied to separate 
experiments that used sham drug application yielded an MI close to 1, significantly higher than for DTX experiments $(\mathrm{P}<0.001, \mathrm{P}=0.007, \mathrm{P}=0.028$ respectively, Wilcoxon's test). For tonic III neurons, the mutual information between control and DTX spike trains was somewhat higher than for other neurons but was similar to that during sham experiments, suggesting DTX had no specific effect on these neurons $(P=0.708)(F i g .5)$. Together, these spike train timing analyses suggest that Kv1 channels are crucial for the specific and reliable encoding of dynamic stimuli in a subset of NA neurons.

Kv1 channel expression drives fluctuation sensitivity by contributing to an adaptive spike threshold. synaptic inputs that cause a rapid rise in the postsynaptic voltage. To determine whether DTX affected the selectivity of NA neurons to rapid changes in their inputs, we measured the spike-triggered average current (STA) of the stimulus preceding each action potential. The peak-to-trough amplitude of the STAs

277 were reduced by application of DTX in the single spike, tonic I, and tonic II neurons (single spiking control amplitude $=0.11 \pm 02 \mathrm{nA}, \mathrm{DTX}$ amplitude $=0.044 \pm 0.01 \mathrm{nA}, \mathrm{n}=11, \mathrm{P}<0.001$, Wilcoxon t-test; tonic I control amplitude $=0.032 \pm 0.005 \mathrm{nA}, \mathrm{DTX}$ amplitude $=0.019 \pm 0.001 \mathrm{nA}, \mathrm{n}=9, \mathrm{P}=0.036$; tonic II control amplitude $=0.031 \pm 0.02 \mathrm{nA}, \mathrm{DTX}$ amplitude $=0.0185 \pm 0.0015 \mathrm{nA}, \mathrm{n}=8, \mathrm{P}=0.014$ ) (Fig 6). In

281 contrast, the peak-trough amplitudes of the STAs for the tonic III and damped neurons were unaltered

282 (tonic III amplitude $=0.015 \pm 0.0013 \mathrm{nA}, \mathrm{DTX}$ amplitude $=0.016 \pm 0.003 \mathrm{nA}, \mathrm{n}=16, \mathrm{P}=0.73$; damped

283 control amplitude $=0.013 \pm 0.003 n A$, DTX amplitude $=0.013 \pm 0.003 n A, n=5, P=0.95)$. A large STA

284 amplitude indicates that the neuron will only fire to rapidly rising inputs, so a reduction in STA amplitude 285 implies a corresponding reduction in selectivity. 
'differentiators', in contrast to 'integrator' neurons whose firing rates reflected the mean stimulus level regardless of the size of the noise fluctuations around the mean (39). To determine whether $\mathrm{G}_{\mathrm{KLT}}$ affected fluctuation sensitivity, we measured the $f$-I curves using current steps with two noise fluctuation amplitudes $(2 \sigma, 4 \sigma$ and $8 \sigma)$ before and after DTX application. In 15 tonic firing NA neurons classified as differentiators (one control example shown in Fig. 7Ai), DTX application elevated firing rates overall (the maximum measured firing rate increased from a mean across 15 neurons of $68.4 \mathrm{~Hz}$ in control to $83.7 \mathrm{~Hz}$ with DTX, data not shown). However, it also reduced the relative firing rate enhancement to larger current noise fluctuations compared to smaller noise fluctuations (Fig. 7Aii).

297 These noise $f$-I curves were quantified by measuring the normalized difference in maximum firing rate (MaxFR Index) between the low noise $(2 \sigma)$ and high noise $(8 \sigma)$ and the normalized firing rate difference over the entire curve (Area Difference Index, ADI) (see Methods). Both these measures are larger in 300 differentiators than in integrators (which are close to the origin, Fig. 8Ai) and decreased significantly 301 with DTX (Fig. 7Bi-Biii MaxFR Index control $=0.388 \pm 0.152$, Differentiator DTX $=0.199 \pm 0.146, n=15, P$ $<0.001$, Student's t-test; ADI control $=0.455 \pm 0.175, \mathrm{DTX}=0.273 \pm 0.158, \mathrm{P}<0.001)$. In contrast, 303 application of DTX had little effect on the noise $f$-I curves in 5 tonic firing NA neurons classified as 304 integrators (Fig. 8A, MaxFR Index control $=0.035 \pm 0.034, \mathrm{DTX}=0.029 \pm 0.0581, \mathrm{n}=5, \mathrm{P}=0.42$, Student's t-test; $A D I$ control $=0.052 \pm 0.072, \mathrm{DTX}=0.043 \pm 0.083, \mathrm{P}=0.39)$. It should be noted that this

306 reduction cannot be explained by a simple proportional increase in all firing rates, which would have had 307 no effect on the normalized indices. Thus blocking $G_{K L T}$ with DTX selectively reduced the fluctuation sensitivity by the differentiator neurons, causing them to behave more like an integrator neuron.

310 proposed to be an adaptive spike threshold $(31,40,41)$. Sodium channel inactivation is a key ion

311 channel mechanism to achieve the adaptation (31), but other conductances that are active in the 312 subthreshold regime have the potential to influence threshold $(32,34,39,42)$. During adaptation, the 
313 voltage threshold dynamically varies depending on the mean voltage, the rate of rise in the voltage, and

314 the time since a preceding action potential. We asked whether the effects described above are

315 consistent with a role for $\mathrm{G}_{\mathrm{KLT}}$ in spike threshold adaptation. To measure spike threshold adaptation, we

316 measured threshold variation during noisy current drive, as previously described in NA neurons (28).

317 With DTX application, the variation in the threshold to the large noise stimulus $(8 \sigma)$ was reduced (Fig9A),

318 and the spike waveforms were more stereotyped (Fig9B, C). Across 15 NA tonic firing neurons, DTX

319 significantly reduced the threshold variation across a range of mean current amplitudes (2-way ANOVA,

320 main effect by drug, $[F(20,345)=10.95, P=0.001] ; P=0.003$ at $0.20 n A, P=0.0021$ at $0.25 n A, P<0.001$ at

3210.30 and $0.35 \mathrm{nA}$, Sidak's multiple comparisons test)(Fig. 9D). These data show that consistent with the

322 reduction in filtering, DTX affects fluctuation sensitivity at least in part due to reduced threshold

323 adaptation. These results suggest that Kv1 channels are involved in threshold adaptation at higher noise

324 levels, possibly in conjunction with sodium channel inactivation.

\section{Discussion}

The role of the low-threshold gated potassium conductance $\left(G_{K L T}\right)$ in the temporal processing of auditory signals has been extensively studied. The $\mathrm{G}_{\mathrm{KLT}}$ conductance is attributed to the expression of members of the Kv1 family of voltage gated potassium channels, particularly Kv1.1 and Kv1.2, that are prevalent throughout the auditory brainstem structures of birds and mammals (14, 15, 22, 43). Distinct

331 from the Kv3 family associated with a high threshold conductance responsible for action potential

332 repolarization (44-46), in vitro studies showed that GKLT activates at membrane potentials near rest

333 and is responsible for the single spiking behavior and outward rectification characteristic of many

334 auditory neurons $(5,6,47-49)$, Activation of $G_{K L T}$ results in a short membrane time constant that

335 prevents the temporal summation of synaptic potentials $(9,50,51)$. Thus the $G_{K L T}$ conductance is a key 
component to phase locking to the fine temporal structure in the acoustic signal and high fidelity

337 sensory encoding in the cochlear nucleus $\operatorname{NM}(3,23,52)$. In the avian interaural time difference (ITD)

338 circuit, dynamic activation of this conductance is crucial for the spike initiation properties that underlie

339 the coincidence detection in the $\mathrm{NL}(5,6,8,22,32,39,53-56)$. Similar effects can be observed in the

340 analogous mammalian circuit $(42,57-61)$.

Pharmacological and immunohistochemical studies, however, have suggested that Kv1 channels

342 are not exclusively expressed in these timing pathways but are also present in the sister cochlear

343 nucleus, NA $(10,22,30)$. In this study, we found that pharmacological blockade of $\mathrm{G}_{\mathrm{KLT}}$, with the

344 Kv1.1/1.2 specific antagonist DTX, dramatically altered the firing phenotypes of some NA neuronal

345 subtypes but not others. Specifically, the single-spiking neurons and the tonic I and tonic II phenotypes

346 lost their unique onset or bursting firing patterns, while the tonic III phenotype that only displayed

347 regular spiking was unchanged. Additionally, we found that the temporal reliability of firing, high-pass

348 filtering characteristics, and spike threshold adaptation were all partially reliant on the DTX-sensitive

349 conductance. These results suggest that Kv1 channels make important contributions to the intrinsic

350 physiological diversity and functional heterogeneity of NA neurons.

Ionic basis of electrophysiological diversity in NA.

Previous work showed that DTX application to single spiking NA neurons converted them into repetitive firing neurons (22). More surprising was the finding that DTX also caused an increase in firing

354 rate in NA tonic firing neurons. We confirmed and extended these results to show that DTX-sensitive

355 changes in firing pattern and rate are related to the physiological classifications in the chick embryonic

356 brain stem described previously (25). The DTX effects were limited to tonic firing neurons that show

357 bursting behavior at lower current stimulus levels. We conclude that the burst termination (tonic I) and

358 delayed burst (tonic II) behaviors both require the presence of a DTX-sensitive conductance, but it 
remains unclear what causes the differences in their response patterns. One explanation could be a other subthreshold conductance present in one type of tonic neuron that interacts with the DTXsensitive current (e.g., an A-type current that could enhance early bursting $(33,34)$. Two neuron types in NA appeared unaffected by DTX: tonic III neurons which best represent canonical rate-coding integrators, and damped neurons, a potential immature phenotype $(22,29)$. In the presence of DTX, the blockade of bursting resulted in responses by all three tonic firing subtypes more closely resembling each other. Because these subtype differences have not been observed in the hatchling (22), it is possible that the increase in excitability and reduction in phenotypic diversity that occurs with

370 development could be due to a downregulation of $\mathrm{G}_{\mathrm{KLT}}$. Examining these neuronal subtypes is important

371 because computational approaches have shown that increased population heterogeneity is directly 372 correlated with increased information encoding capacity (27).

Neurons in the NA utilize Kv1 channels to encode the temporal dynamics of their inputs.

376 for $\mathrm{G}_{\mathrm{KLT}}$ in temporal processing: multi-spiking intrinsic firing properties $(1,22,26)$, poorer phase-locking

377 in vivo to the acoustic fine structure, and a role in interaural level coding $(3,16,23)$. However, a more

378 complex picture of sound processing in NA has been emerging. First, the heterogeneity of in vivo

379 response properties and morphology suggested that NA is not a monolithic rate-coding nucleus, but a

380 diverse population of neurons $(21,25)$, some of which show temporal sensitivity, dynamic feature

381 selectivity, and auditory envelope processing $(19,20,26,28)$. Second, in vitro studies showed a diversity 
of intrinsic features across the population, some of which also demonstrated greater temporal

383 sensitivity than others (25-27). In another study, the differentiator-type intrinsic properties of a subset

384 of NA neurons could account for the intensity-dependent bandpass behavior in vivo (19). In their model,

385 the high-pass filtering due to active intrinsic membrane properties of the tonic-firing, coincidence-

386 detector-like neurons combined with the low-pass filter behavior of the synaptic inputs and passive

387 membrane properties resulted in the overall bandpass filtering. Interestingly, variation in the properties

388 across the neuronal population produced an array of bandpass properties spanning the physiological

389 response space. The results presented in the present study provides direct evidence that variations in

390 Kv1 conductances contribute to the variations in temporal processing properties in vitro; it remains to

391 be tested whether a mature circuit in vivo would also require these properties to encode

392 spectrotemporal auditory information. Neurons with high reliability should be capable of encoding more

393 rapidly changing components of the acoustic signal, such the onsets and gaps that are key features of

394 speech and other communication signals. Neurons with less reliability are likely to be important for

395 encoding the more slowly changing aspects of the acoustic signal, such as slower envelope variations or

396 ongoing interaural level cues. Together, these studies suggest that NA neurons function on a spectrum

397 of operating modes, ranging from pure integrators to pure coincidence-detectors (34).

Spike threshold adaptation in NA neurons may rely on the low threshold potassium conductance.

The operating mode diversity observed across NA specifically appears to arise from a

400 mechanism known as spike-threshold adaptation, a phenomenon by which the voltage threshold is

401 modulated by spike history and membrane voltage mean and rate of rise $(19,63-65)$. This form of

402 adaptation is the probable mechanism underlying the selective responsiveness of NA neurons to rapid

403 rises in the postsynaptic voltage, acting like a high-pass filter and enhancing the firing response to

404 temporally modulated inputs. Spike threshold adaptation is a process that occurs throughout the brain, 
particularly in cortical pyramidal neurons, and auditory brainstem neurons $(19,28,31,32,66,67)$. In NA,

406 threshold adaptation drives NA neurons to encode amplitude modulations with higher fidelity than

407 auditory nerve fibers (19) as well as diversifies their operating modes (28). Phenomenological models

408 based on sodium channel inactivation as a mechanism were successful at recapitulating the firing

409 responses $(19,28)$, however these models use abstract conductance representations that do not

410 specifically rule out other non-sodium, subthreshold conductances, such as the Kv1 channel. In a study

411 of cortical neurons, blockade of Kv1 channels with DTX largely eliminated spike threshold adaptation

412 (32). Our results suggest a similar role for Kv1 in NA neurons.

413 Functional analogs of NA neurons in the mammalian cochlear nucleus

414 The mammalian auditory brain stem is not anatomically homologous to the avian auditory brain

415 stem. The mammalian ventral cochlear nucleus (VCN) has functionally similar cell types to those in NA,

416 but there does not appear to be a one-to-one match for each type. For example, the spherical bushy

417 cells of the VCN are analogous to the avian NM neurons in that both have high levels of Kv1 expression,

418 receive calyceal inputs from auditory nerve fibers, generate precise spiking phase-locked to the fine

419 structure in auditory signals and project to analogous coincidence detection circuits (68). The T-stellate

420 cells of the VCN appear to be the closest functional analog to NA neurons, in that they have reduced

421 phase-locking relative to auditory nerve inputs, repetitive intrinsic firing properties, encode envelope

422 and intensity information for spectrotemporal coding, and project directly to the midbrain inferior

423 colliculus $(1,12,69-74)$. Identified T-stellate neurons lack any significant low threshold potassium

424 channel conductance and are insensitive to DTX (75-78). These results suggest that the T-stellate

425 neurons of the VCN are not functionally analogous to the DTX-sensitive neurons in NA (tonic I/tonic II

426 subtypes), but instead may be more similar to the DTX-insensitive, integrator like neurons of NA (tonic III

427 subtype). Another study, using acutely dissociated neurons and voltage clamp, suggested there was a 
428 population of neurons in the VCN with intermediate levels of DTX-sensitive, lower-threshold

429 conductances, possibly corresponding to the radiate (or D-stellate) type of multipolar neurons, a less

430 common type of repetitively firing neuron in the AVCN that projects to the dorsal cochlear nucleus (72,

431 79-81). The recent discovery in the VCN of a third stellate neuron population, dubbed L-stellate, which

432 appears to provide narrowband inhibition and operates within a feedback loop with T-stellate neurons

433 (82) further suggests there may be greater phenotypical diversity than previously appreciated. How

434 these cell types may correspond to NA cell types remains to be seen. These multi-spiking neurons in VCN

435 can entrain to high frequency stimuli in vitro, but the reliability of responses to the noisy, temporally

436 modulated stimuli we describe in the present study have only been tested in DCN neurons (36).

437 Comparisons between NA and VCN are complicated by the fact that VCN contains a dense network of

438 lateral connectivity and local inhibition, while NA appears to be a strictly feedforward circuit without

439 local inhibition, so their feature selectivity and computational roles are likely to be quite dissimilar. Also

440 limiting comparisons of intrinsic properties across studies are species differences (chick vs guinea pig vs

441 mouse) and the possible confounding effect of temperature on the kinetics of the ion channels $(78,83)$.

\section{Summary}

In summary, we have demonstrated that dendrotoxin-sensitive conductances are prevalent in a

444 subpopulation of NA neurons and are critical for the temporal response properties in these neurons. By

445 enhancing spike threshold adaptation, this conductance underlies the spike timing reliability, high-pass

446 membrane filtering, and fluctuation sensitivity properties of the differentiator subtypes. The regulation

447 of the Kv1 family of channels may be a key driver of intrinsic electrophysiological diversity in the avian

448 cochlear nucleus and contribute to spectrotemporal auditory feature selectivity in vivo. 
bioRxiv preprint doi: https://doi.org/10.1101/2021.10.08.463546; this version posted October 9, 2021. The copyright holder for this preprint

(which was not certified by peer review) is the author/funder, who has granted bioRxiv a license to display the preprint in perpetuity. It is made available under aCC-BY-NC 4.0 International license.

450

451

452 Acknowledgements

453 Support for this research was provided by NIH grant R01DC10000. The authors thank Felix Bartsch for

454 his helpful advice and MATLAB code for the mutual information analysis.

455

456 

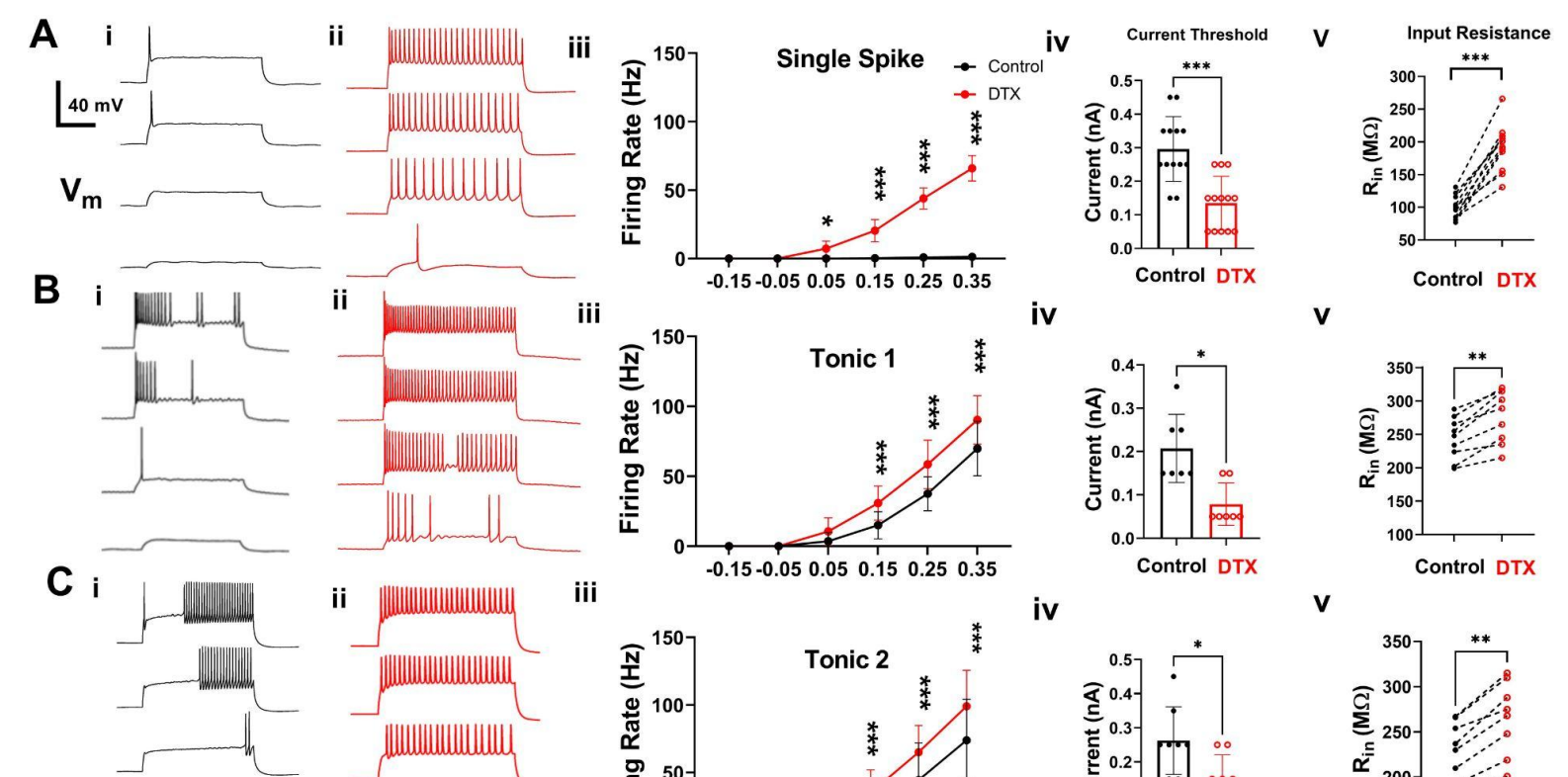

iii

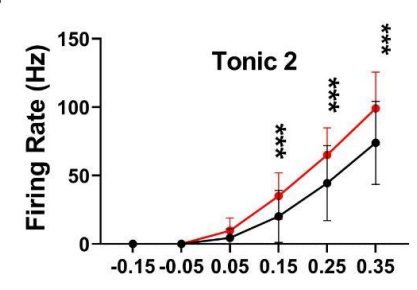

iv

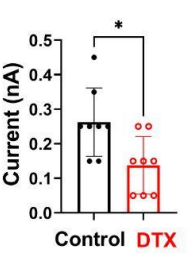

V
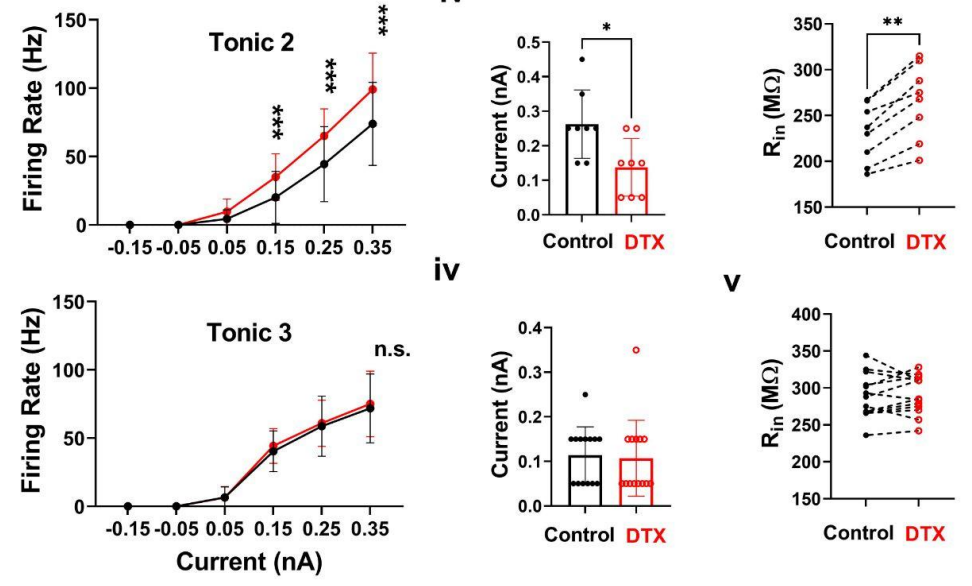

V

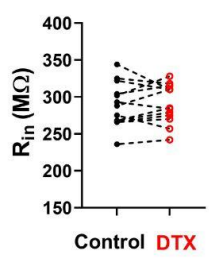

Fig. 1. Dendrotoxin altered the spiking responses in a subset of NA neurons. Voltage

responses were elicited by a set of current injections of increasing amplitude into NA neurons comprising 4 major cell types: single-spiking (row A) and 3 subtypes of tonic firing neurons: tonic I (row $\mathrm{B}$ ), tonic II (row C), and tonic III (row D). Example traces show matched responses during control conditions (Ai-Di) and following DTX application (Aii-Dii). In DTX, firing rate increased in single-spike, tonic I, and tonic II neurons (Aiii: $\mathrm{P}<0.001$; Biii: $\mathrm{P}<0.001$, Ciii: $\mathrm{P}<0.001,2$-way ANOVA) but not in tonic III neurons (Diii, $P=0.25$ ). Asterisks indicate Sidak's post hoc multiple comparisons test significance, ${ }^{*} P$ $<0.05, * * * \mathrm{P}<0.001)$. The current amplitude threshold (rheobase) was also significantly reduced (Ai: $\mathrm{P}$ < 0.001; Biv: $P=0.03$; Civ: $P=0.03$, Wilcoxon's signed rank test) except in tonic III neurons (Div, $P$ > 0.99). Input resistance increased in single-spike, tonic $I$, and tonic II neurons (Av: $P=0.001 ; B v: P=$ 0.039, and Cv: $P=0.042$, Student's t-test) except in tonic III neurons (Dv: $P>0.99$ ). 


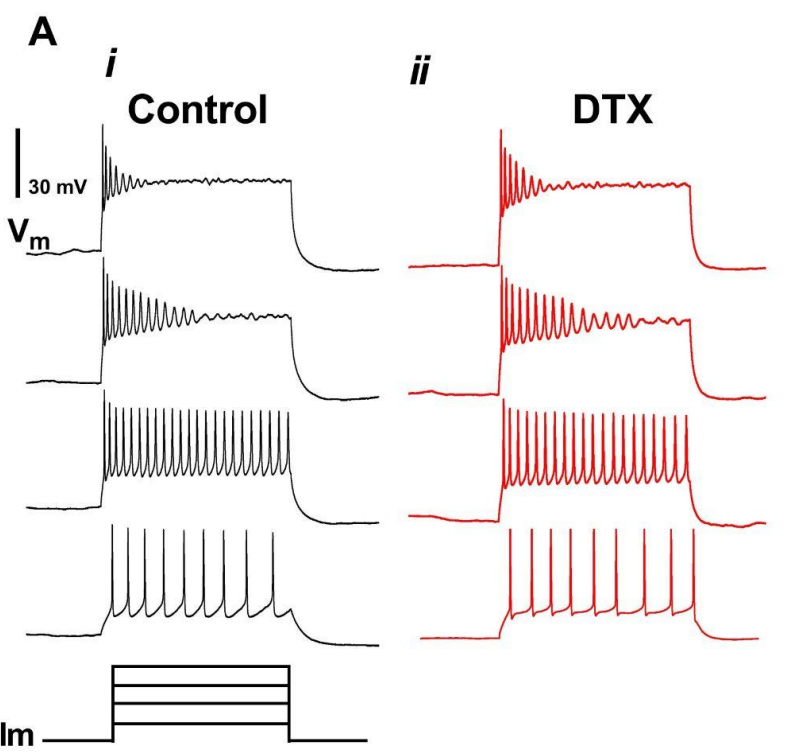

B

C

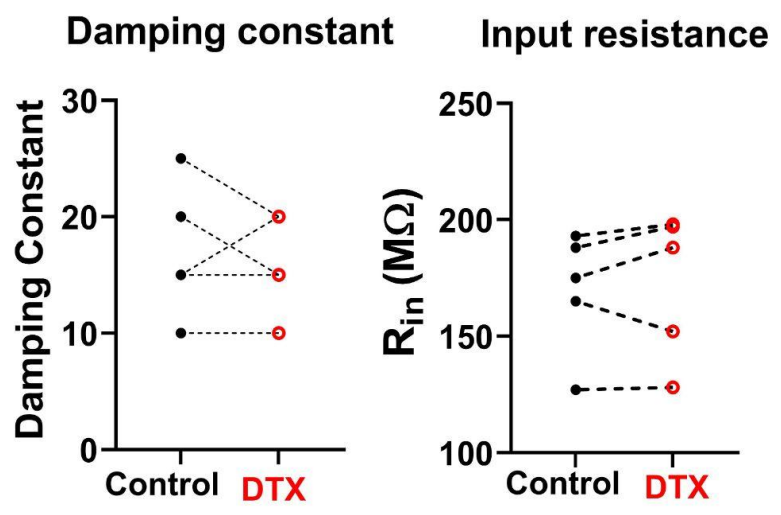

Fig. 2. DTX did not alter firing or intrinsic properties of damped neurons. Voltage responses in response to flat current injections (400 ms duration) showed no apparent change between control (Ai) and after DTX application (Aii). The damping constant (B) and input resistance (C) were unchanged (control damping constant $=19.0 \pm 6.3$ (mean \pm SD), DTX damping constant $=18.2 \pm 5.2, P=0.97$; control $R_{\text {in }}=168.3 \pm 22.4 \mathrm{M} \Omega, D T X R_{\text {in }}=174.8 \pm 26,7 \mathrm{M} \Omega, P>0.99$, Student's $t$ test). 
A

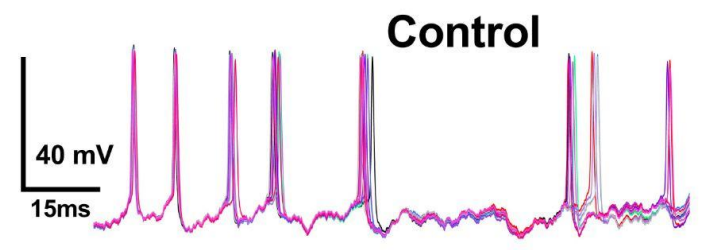

Vm

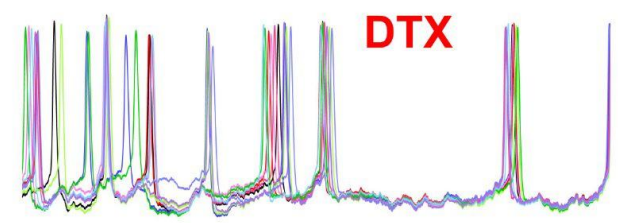

Im

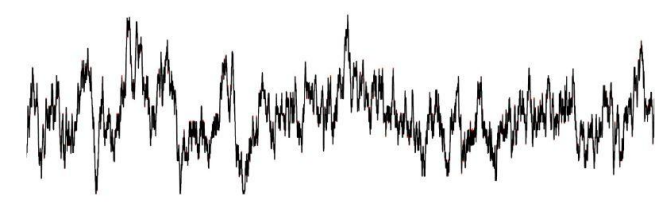

B

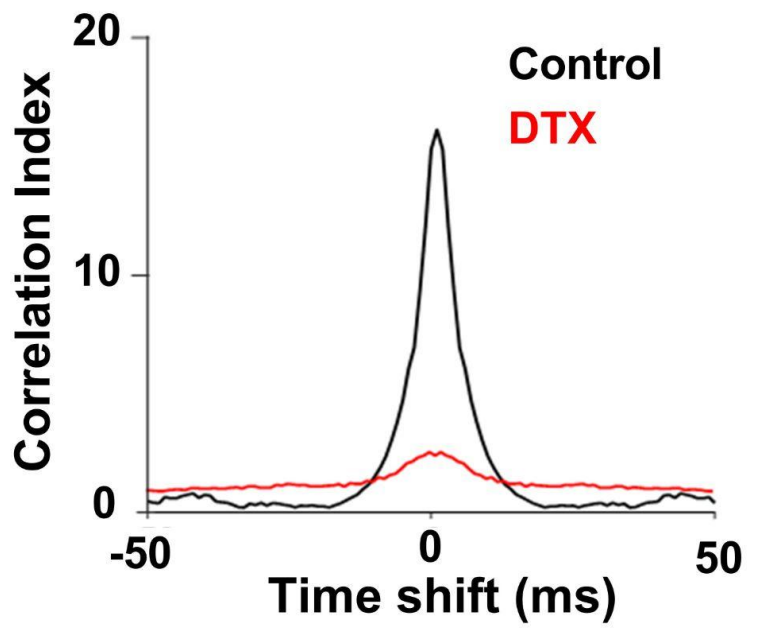

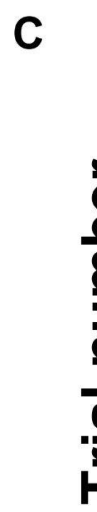

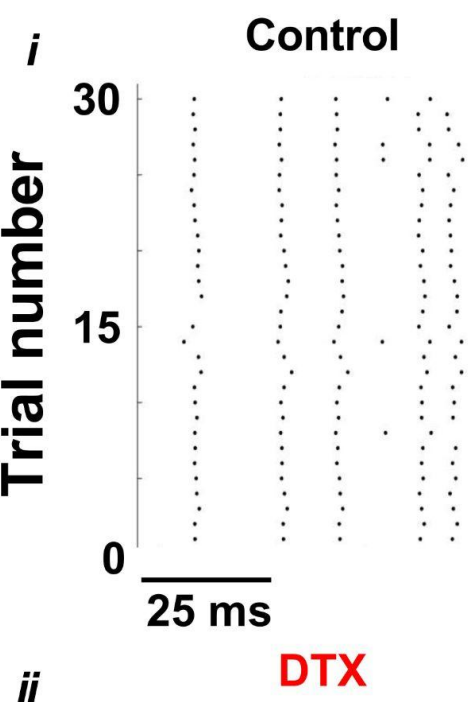

ii

30

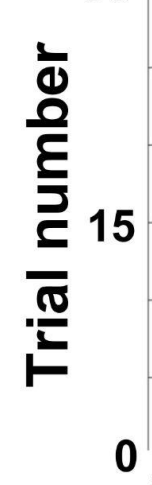

$\overline{25 \mathrm{~ms}}$

Fig. 3. DTX reduced the spike timing reliability in a tonic II neuron in NA. A) Overlaid voltage traces $\left(V_{m}\right)$ for seven repetitions of an identical "noisy" current $\left(I_{m}\right)$ stimulus in control and $100 \mathrm{nM}$ DTX conditions. Only the first $150 \mathrm{~ms}$ of the 2 second long stimulus is shown. B) Raster plots of all 30 trials for each condition, first $100 \mathrm{~ms}$ of response (onset at $0 \mathrm{~ms}$ ). C) Spike timing reliability quantified with a shuffled autocorrelogram showed a reduced peak correlation index and broader distribution for responses in the presence of DTX. 
A
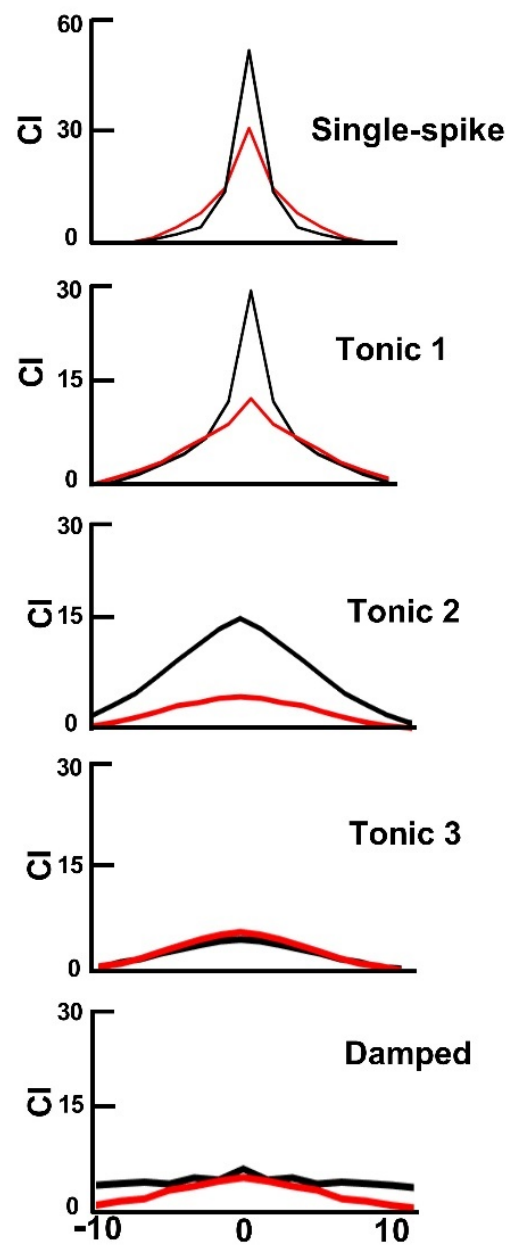
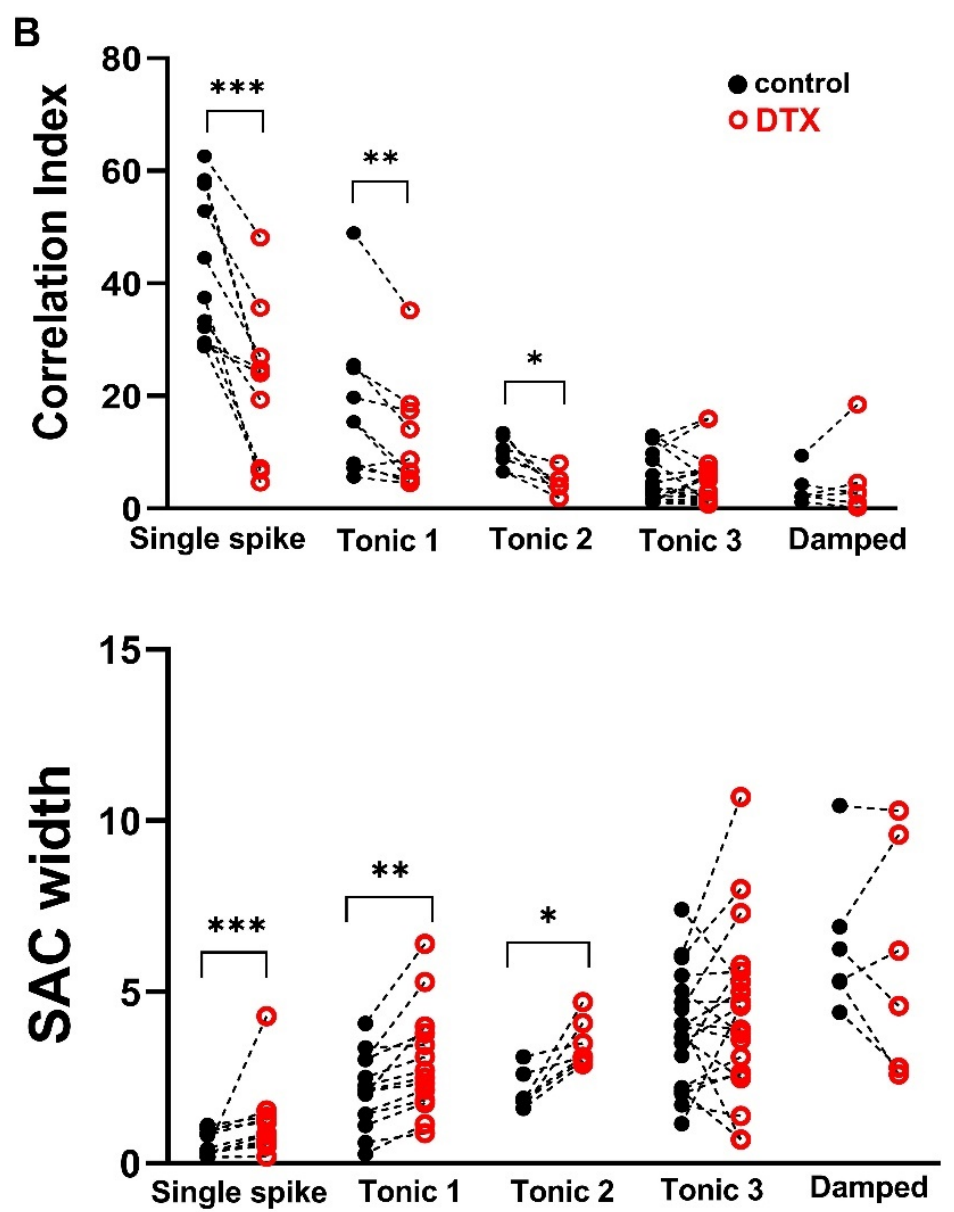
across all neurons recorded for each of the 5 cell types (control, black, DTX, red). (B) Summary data of SAC parameters peak correlation index $(\mathrm{Cl})$ (top) and full width at half-maximum height (FWHM) (bottom). Peak $\mathrm{Cl}$ decreased in single-spike, tonic $\mathrm{I}$, and tonic II neurons $(\mathrm{P}<0.001, \mathrm{P}=0.0028, \mathrm{p}=$ 

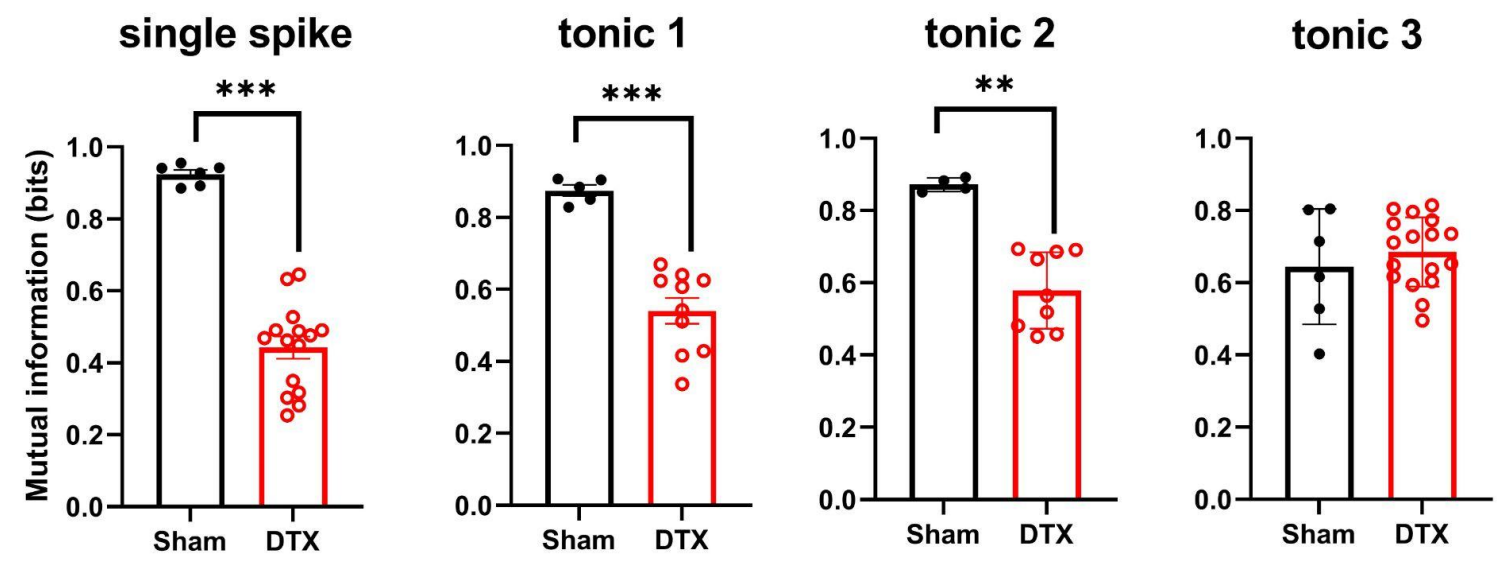

Fig. 5. Mutual information (MI) between spike trains by cell type. MI between control spike

508 trains and spike trains following sham solution change was high (black markers, bars) indicating high

509 similarity. In contrast, MI between spike trains from control versus DTX trials was significantly lower for

510 single-spike, tonic I, and tonic II neurons but not for tonic III neurons (Mann-Whittney test, $\mathrm{P}<0.001, \mathrm{P}<$

$5110.001, P=0.003$ and $P=0.707$, respectively). 


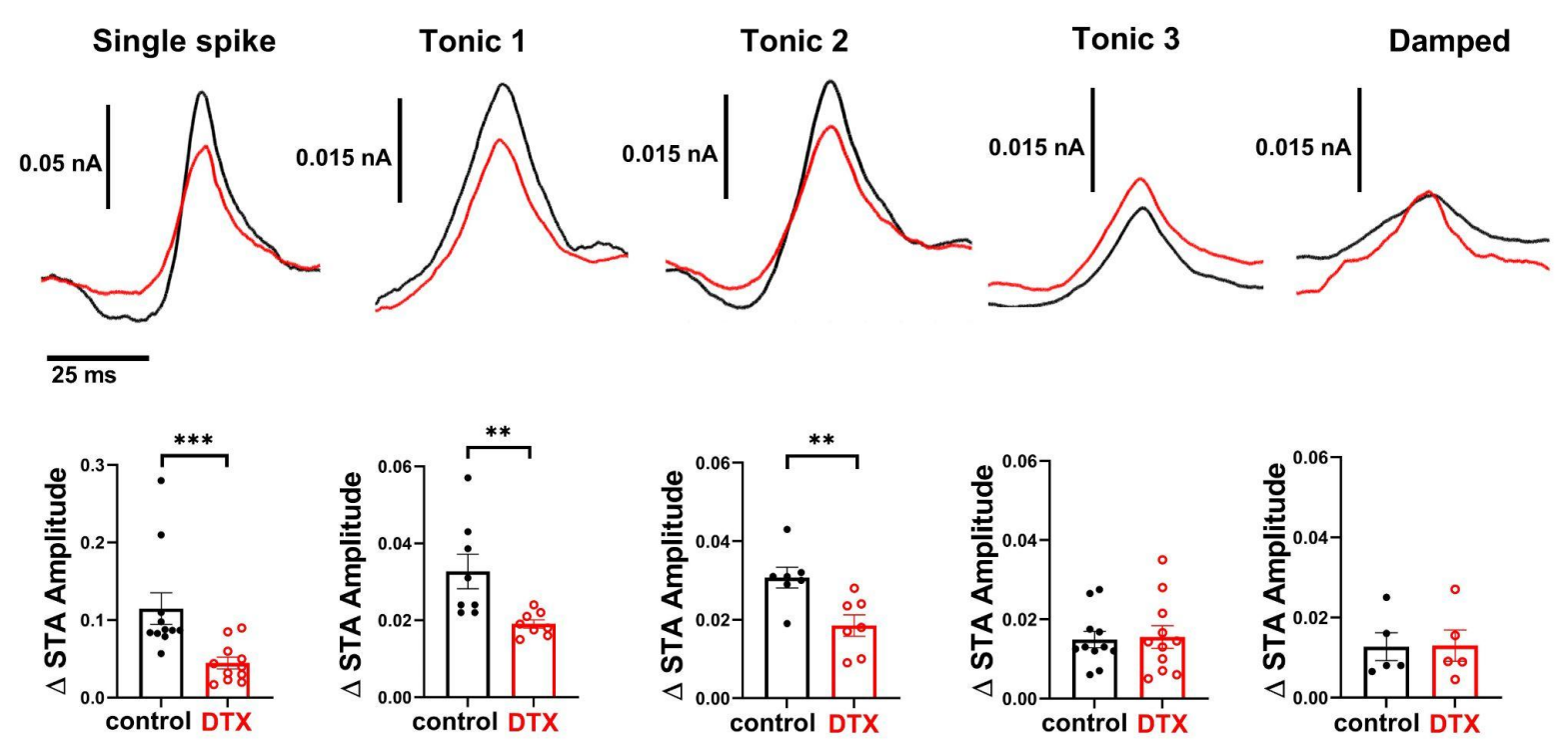

Fig. 6. DTX reduced the high-pass response selectivity in a subset of NA neurons. Top row: spike-triggered averages (STA) for each neuron type before (black traces) and after (red traces) DTX application. Traces are grand averages of the population for each cell type. Bottom row: summary statistics of peak-to-trough amplitude of STA waveforms from individual neurons. STA amplitudes were significantly reduced in the presence of DTX for single-spiking, tonic $I$, and tonic II neurons $(P<0.001, P$ $=0.036, P=0.014$, respectively, Wilcoxon's t-test). Tonic III and damped neuron STAs were unchanged. 
A

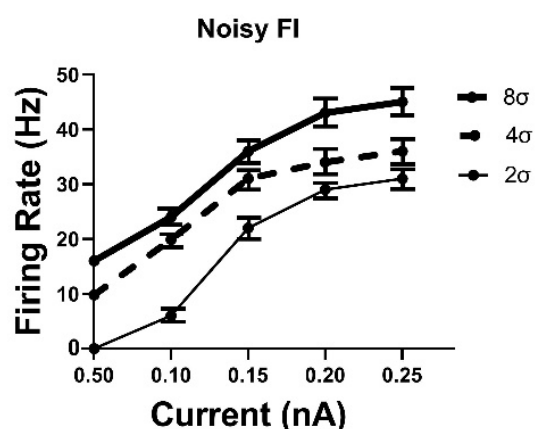

B$$
\text { i }
$$

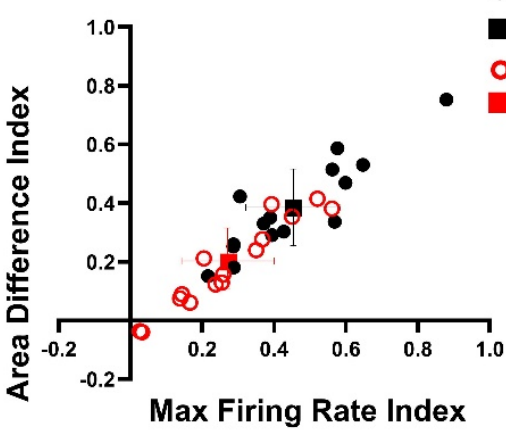

ii

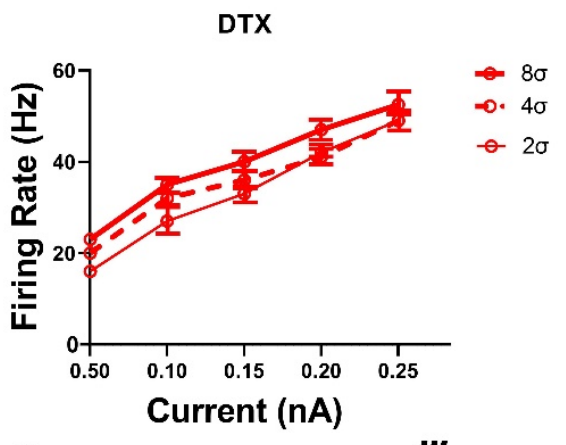

ii

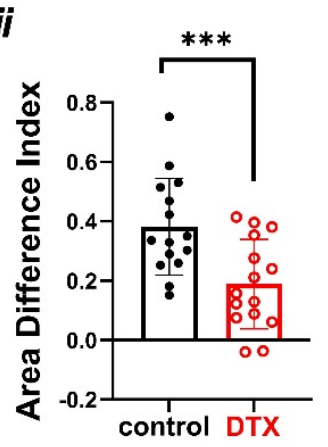

iii

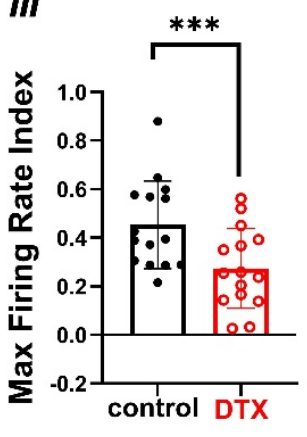

Fig. 7. DTX diminished fluctuation sensitivity in differentiators. (A)An example of one differentiator neuron's input-output function with 3 levels of noise before (i) and after DTX application (ii). (B) Summary plot of $\mathrm{f}-\mathrm{I}$ curve metrics for 15 differentiator neurons ( $\mathrm{Bi}$, black solid and red open markers represent before and after pairs; square markers with error bars are group mean $\pm S D$ ). (Bii) Area Difference Index (control ADI $=0.391 \pm 0.17$, DTX ADI $=0.187 \pm 0.15$ ) and (Biii) maximum firing rate index (control $\triangle \operatorname{maxFR}=0.422 \pm 0.19$, DTX $\triangle \operatorname{maxFR}=0.261 \pm 0.15$ ) are reduced upon DTX application. 
A

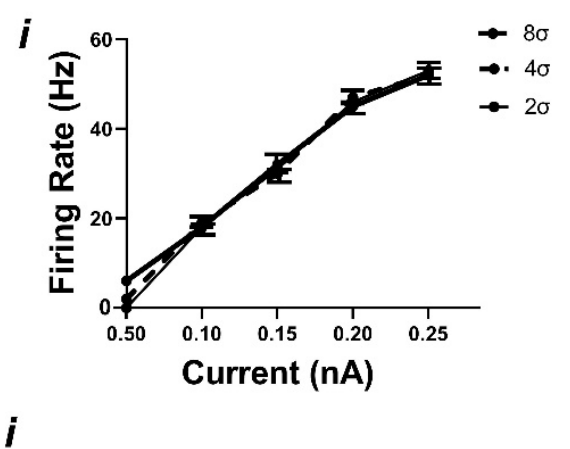

B

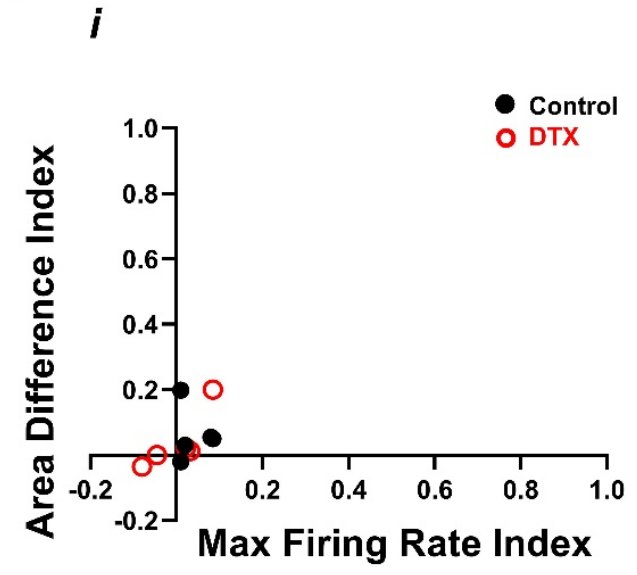

\section{ii}

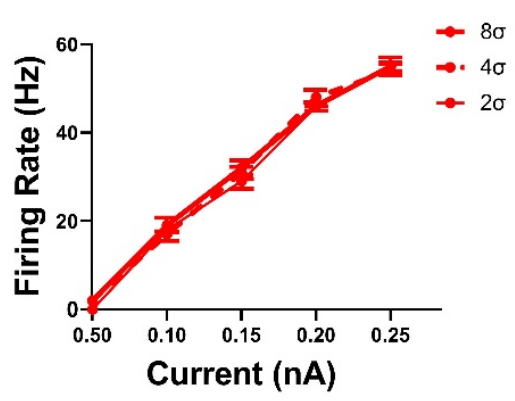

ii

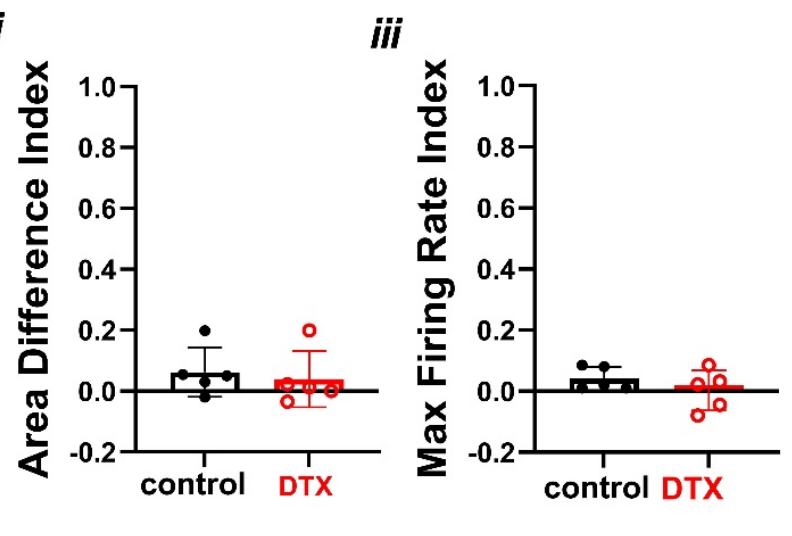

Fig. 8. DTX had no impact on fluctuation sensitivity metrics in integrators. Panels as in Fig. 9. Difference Index (control ADI $=0.042 \pm 0.14$, DTX ADI $=0.032 \pm 0.025$ ) and (Biii) maximum firing rate index (control $\triangle \operatorname{maxFR}=0.036 \pm 0.017$, DTX $\triangle \operatorname{maxFR}=0.008 \pm 0.072$ ) show no changes with DTX. 

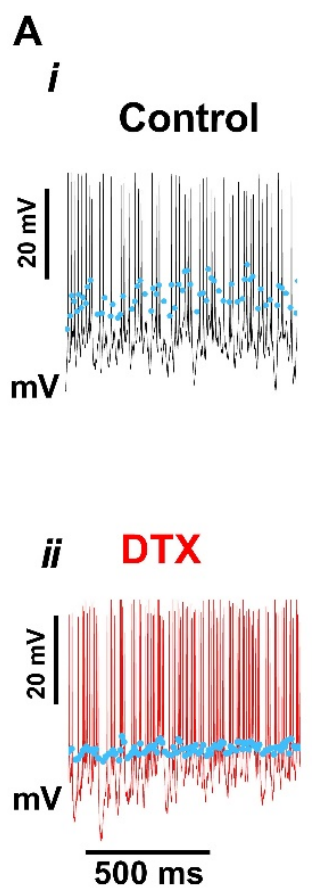

B
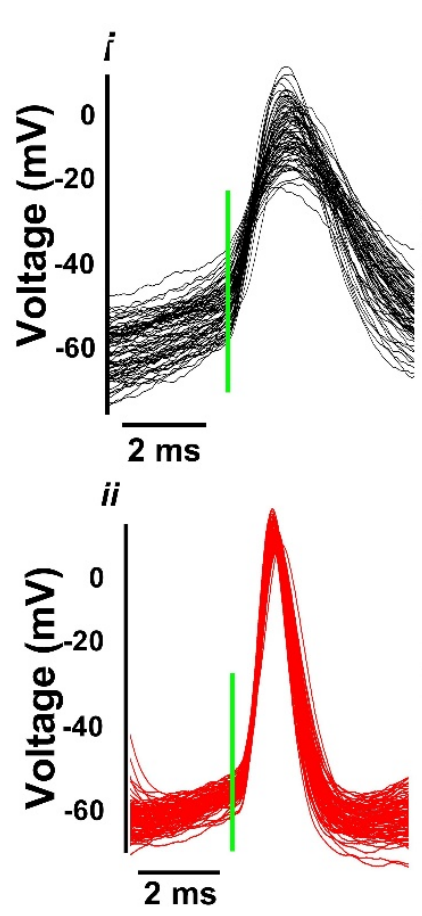

C
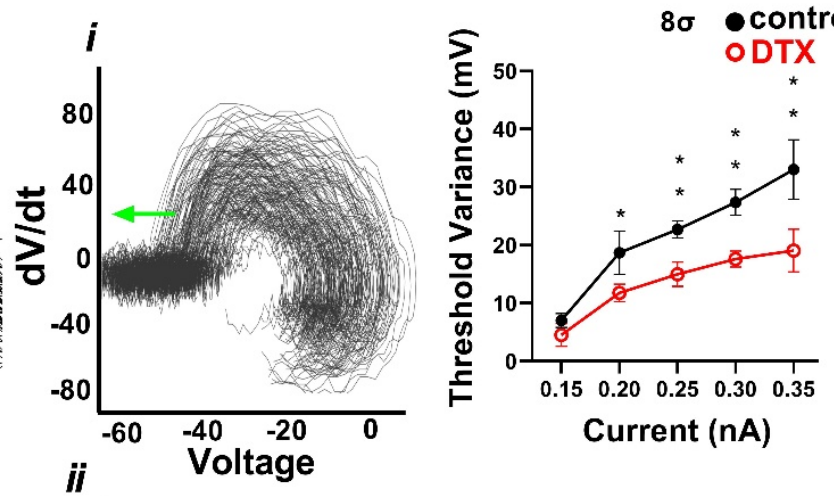

Figure 9 DTX altered the dynamics of action potential initiation and threshold variability during periods of high current fluctuation (A) Example spike trains with spike thresholds indicated by blue dots in a control (i) and post-DTX application (ii). (B) Action potentials overlaid for control (i) and DTX (ii) trials aligned on spike threshold (green bar). (C) Voltage derivative versus voltage for APs in panel B for control (i) and DTX (ii). dV/dt threshold is labeled with a green arrow. (D) Threshold variability was significantly diminished in the $8 \sigma$ noise fluctuation level from $0.2 \mathrm{nA}$ and greater (2-way ANOVA, main effect by drug, $[F(20,345)=10.95, P=0.001] ; 0.2 n A: P=0.0085 ; 0.25 n A: P=0.0041 ; 0.3$ $n A: P=0.001 ; 0.35$ nA: $P=0.001$; Sidak's multiple comparisons test). 


\section{References}

1. Carr CE, Soares D. Evolutionary convergence and shared computational principles in the auditory system. Brain Behav Evol 59: 294-311, 2002. doi: 10.1159/000063565.

564 2. Sachs MB, Sinnott JM. Responses to tones of single cells in nucleus magnocellularis and nucleus 565 angularis of the redwing blackbird (Agelaius phoeniceus). J Comp Physiol A 126: 347-361, 1978. the barn owl. J Neurosci 4: 1787-1799, 1984. doi: 10.1523/jneurosci.04-07-01787.1984.

568 4. Raman IM, Trussell LO. The kinetics of the response to glutamate and kainate in neurons of the avian 569 cochlear nucleus. Neuron 9: 173-186, 1992. doi: 10.1016/0896-6273(92)90232-3. magnocellularis. J Neurophysiol 80: 2824-2835, 1998. doi: 10.1152/jn.1998.80.6.2824.

572 6. Reyes AD, Rubel EW, Spain WJ. Membrane properties underlying the firing of neurons in the avian 573 cochlear nucleus. J Neurosci 14: 5352-5364, 1994. Cochlear Nucleus Magnocellularis. J Exp Neurosci 9: 11-24, 2015. doi: 10.4137/jen.s25472.

576 8. Ohmori H. Neuronal specializations for the processing of interaural difference cues in the chick. Front 577 Neural Circuit 8: 47, 2014. doi: 10.3389/fncir.2014.00047. Expression in Avian Cochlear Nucleus during Late Development. J Neurosci 38: 2967-2980, 2018. doi:

$580 \quad 10.1523 /$ jneurosci.2472-17.2018.

581 10. Lu Y, Monsivais P, Tempel BL, Rubel EW. Activity-dependent regulation of the potassium channel 582 subunits Kv1.1 and Kv3.1. J Comp Neurol 470: 93-106, 2004. doi: 10.1002/cne.11037.

583 11. Koyano K, Funabiki K, Ohmori H. Voltage-gated ionic currents and their roles in timing coding in 584 auditory neurons of the nucleus magnocellularis of the chick. Neurosci Res 26: 29-45, 1996. doi:

585 10.1016/0168-0102(96)01071-1. 2865-2880, 1991. doi: 10.1523/jneurosci.11-09-02865.1991.

588 13. Wu SH, Oertel D. Intracellular injection with horseradish peroxidase of physiologically characterized 589 stellate and bushy cells in slices of mouse anteroventral cochlear nucleus. J Neurosci 4: 1577-1588, 590 1984. doi: 10.1523/jneurosci.04-06-01577.1984. 
14. Brew HM, Forsythe ID. Two voltage-dependent $\mathrm{K}+$ conductances with complementary functions in postsynaptic integration at a central auditory synapse. J Neurosci 15: 8011-8022, 1995.

593 15. Johnston J, Forsythe ID, Kopp-Scheinpflug C. Going native: voltage-gated potassium channels

594 controlling neuronal excitability. J Physiol 588: 3187-3200, 2010. doi: 10.1113/jphysiol.2010.191973.

595 16. Konishi M, Sullivan WE, Takahashi T. The owl's cochlear nuclei process different sound localization 596 cues. J Acoust Soc Am 78: 360-364, 1985. doi: 10.1121/1.392499.

597 17. Takahashi TT, Konishi M. Projections of the cochlear nuclei and nucleus laminaris to the inferior 598 colliculus of the barn owl. J Comp Neurol 274: 190-211, 1988. doi: 10.1002/cne.902740206.

599 18. Viete S, Peña JL, Konishi M. Effects of Interaural Intensity Difference on the Processing of Interaural 600 Time Difference in the Owl's Nucleus Laminaris. J Neurosci 17: 1815-1824, 1997. doi:

601 10.1523/jneurosci.17-05-01815.1997.

19. Fontaine B, MacLeod KM, Lubejko ST, Steinberg L, Köppl C, Peña JL. Emergence of band-pass filtering through adaptive spiking in the owl's cochlear nucleus. J Neurophysiol 112: 430-445, 2014. doi: 604 10.1152/jn.00132.2014.

20. Steinberg L, Peña JL. Difference in Response Reliability Predicted by Spectrotemporal Tuning in the Cochlear Nuclei of Barn Owls. J Neurosci 31: 3234-3242, 2011. doi: 10.1523/jneurosci.5422-10.2011.

607 21. Soares D, Carr CE. The cytoarchitecture of the nucleus angularis of the barn owl (Tyto alba). J Comp 608 Neurol 429: 192-205, 2001. the nucleus angularis of the chicken. J Physiol 548: 219-232, 2003. doi: 10.1113/jphysiol.2002.036285.

611 23. Warchol ME, Dallos P. Neural coding in the chick cochlear nucleus. J Comp Physiol 166: 721-734, 612 1990. doi: 10.1007/bf00240021.

613 24. Köppl C, Carr CE. Computational Diversity in the Cochlear Nucleus Angularis of the Barn Owl. J 614 Neurophysiol 89: 2313-2329, 2003. doi: 10.1152/jn.00635.2002.

615 25. Soares D, Chitwood RA, Hyson RL, Carr CE. Intrinsic Neuronal Properties of the Chick Nucleus 616 Angularis. J Neurophysiol 88: 152-162, 2002. doi: 10.1152/jn.2002.88.1.152. both integration and encoding of temporally modulated noisy inputs in vitro. J Neurophysiol 108: 2794619 2809, 2012. doi: 10.1152/jn.00092.2012. properties among cochlear nucleus neurons improves the population coding of temporal information. $J$ 
28. Lubejko ST, Fontaine B, Soueidan SE, MacLeod KM. Spike threshold adaptation diversifies neuronal operating modes in the auditory brain stem. J Neurophysiol 122: 2576-2590, 2019. doi:

625 10.1152/jn.00234.2019.

29. Brown DH, Hyson RL. Intrinsic physiological properties underlie auditory response diversity in the avian cochlear nucleus. J Neurophysiol 121: 908-927, 2019. doi: 10.1152/jn.00459.2018.

628 30. Bloom S, Williams A, MacLeod KM. Heterogeneous calretinin expression in the avian cochlear 629 nucleus angularis. J Assoc Res Otolaryngology 15: 603-620, 2014. doi: 10.1007/s10162-014-0453-0.

630 31. Platkiewicz J, Brette R. A threshold equation for action potential initiation. PLoS Comput Biol 6: e1000850, 2010. doi: 10.1371/journal.pcbi.1000850.

632 32. Higgs $M H$, Spain WJ. Kv1 channels control spike threshold dynamics and spike timing in cortical 633 pyramidal neurones. J Physiol 589: 5125-5142, 2011. doi: 10.1113/jphysiol.2011.216721. distinct tuning properties that enable neurons to encode the integral or derivative of their input. Front Cell Neurosci 8: 452, 2015. doi: 10.3389/fncel.2014.00452. to Resonators Under In Vivo-Like Conditions. J Neurophysiol 100: 3030-3042, 2008. doi:

639 10.1152/jn.90634.2008.

640 35. Joris PX, Louage DH, Cardoen L, Heijden M van der. Correlation index: a new metric to quantify 641 temporal coding. Hearing Res 216-217: 19-30, 2006. doi: 10.1016/j.heares.2006.03.010. Neurophysio/ 97: 4162-4172, 2007. doi: 10.1152/jn.00469.2006.

644 37. Steveninck RR de R van, Lewen GD, Strong SP, Koberle R, Bialek W. Reproducibility and variability in 645 neural spike trains. Science 275: 1805-1808, 1997. doi: 10.1126/science.275.5307.1805. 10.1002/j.1538-7305.1948.tb01338.x.

648 39. Higgs MH, Slee SJ, Spain WJ. Diversity of gain modulation by noise in neocortical neurons: regulation by the slow afterhyperpolarization conductance. J Neurosci 26: 8787-8799, 2006. doi: 10.1523/jneurosci.1792-06.2006. fluctuations depends on time scale separation between fast and slow variables in single neurons. $J$ Comput Neurosci 27: 277-290, 2009. doi: 10.1007/s10827-009-0142-x. doi: 10.1371/journal.pcbi.1004761. 
42. Svirskis G, Kotak V, Sanes DH, Rinzel J. Sodium Along With Low-Threshold Potassium Currents Enhance Coincidence Detection of Subthreshold Noisy Signals in MSO Neurons. J Neurophysiol 91: 24652473, 2004. doi: 10.1152/jn.00717.2003.

43. Dodson PD, Billups B, Rusznák Z, Szûcs G, Barker MC, Forsythe ID. Presynaptic rat Kv1.2 channels suppress synaptic terminal hyperexcitability following action potential invasion. J Physiol 550: 27-33, 2003. doi: 10.1113/jphysiol.2003.046250.

44. Parameshwaran S, Carr CE, Perney TM. Expression of the Kv3.1 Potassium Channel in the Avian Auditory Brainstem. J Neurosci 21: 485-494, 2001. doi: 10.1523/jneurosci.21-02-00485.2001.

45. Wang LY, Gan L, Forsythe ID, Kaczmarek LK. Contribution of the Kv3.1 potassium channel to highfrequency firing in mouse auditory neurones. J Physiology 509 ( Pt 1): 183-194, 1998. doi: 10.1111/j.1469-7793.1998.183bo.x.

46. Choudhury N, Linley D, Richardson A, Anderson M, Robinson SW, Marra V, Ciampani V, Walter SM, Kopp-Scheinpflug C, Steinert JR, Forsythe ID. Kv3.1 and Kv3.3 subunits differentially contribute to Kv3 channels and action potential repolarization in principal neurons of the auditory brainstem. $J$ Physiol 598: 2199-2222, 2020. doi: 10.1113/jp279668. detection in the nucleus laminaris of the chicken. J Physiol 540: 529-542, 2002. doi:

674 10.1113/jphysiol.2001.013365.

675 48. Kuba H. Cellular and molecular mechanisms of avian auditory coincidence detection. Neurosci Res 676 59: 370-376, 2007. doi: 10.1016/j.neures.2007.08.003.

677 49. Zhang S, Trussell LO. A characterization of excitatory postsynaptic potentials in the avian nucleus 678 magnocellularis. J Neurophysiol 72: 705-718, 1994. doi: 10.1152/jn.1994.72.2.705.

679 50. Fukui I, Ohmori H. Tonotopic gradients of membrane and synaptic properties for neurons of the 680 chicken nucleus magnocellularis. J Neurosci 24: 7514-7523, 2004. doi: 10.1523/jneurosci.0566-04.2004. source of inhibitory feedback for coincidence detection in the avian auditory brainstem. J Neurosci 19:

$683 \quad 2313-2325,1999$.

684 52. Ashida G, Tollin DJ, Kretzberg J. Physiological models of the lateral superior olive. PLoS Comput Biol 685 13: e1005903, 2017. doi: 10.1371/journal.pcbi.1005903.

686 53. Reyes AD, Rubel EW, Spain WJ. In vitro analysis of optimal stimuli for phase-locking and time687 delayed modulation of firing in avian nucleus laminaris neurons. J Neurosci 16: 993-1007, 1996. 
55. Kuba H, Yamada R, Fukui I, Ohmori H. Tonotopic specialization of auditory coincidence detection in nucleus laminaris of the chick. J Neurosci 25: 1924-1934, 2005. doi: 10.1523/jneurosci.4428-04.2005.

56. Carr CE, Konishi M. A circuit for detection of interaural time differences in the brain stem of the barn owl. J Neurosci 10: 3227-3246, 1990.

57. Golding NL, Robertson D, Oertel D. Recordings from slices indicate that octopus cells of the cochlear nucleus detect coincident firing of auditory nerve fibers with temporal precision. J Neurosci 15: 31383153, 1995.

58. Khurana S, Remme MWH, Rinzel J, Golding NL. Dynamic Interaction of Ih and IK-LVA during Trains of Synaptic Potentials in Principal Neurons of the Medial Superior Olive. J Neurosci 31: 8936-8947, 2011. doi: 10.1523/jneurosci.1079-11.2011.

59. Khurana S, Liu Z, Lewis AS, Rosa K, Chetkovich D, Golding NL. An essential role for modulation of hyperpolarization-activated current in the development of binaural temporal precision. $J$ Neurosci 32: 2814-2823, 2012. doi: 10.1523/jneurosci.3882-11.2012.

60. Matthews G, Fuchs P. The diverse roles of ribbon synapses in sensory neurotransmission. Nat Rev Neurosci 11: 812-822, 2010. doi: 10.1038/nrn2924. small inputs by a low-threshold outward current in auditory neurons. J Neurosci 22: 11019-11025, 2002. cochlear nucleus. J Neurosci 28: 11906-11915, 2008. doi: 10.1523/jneurosci.3827-08.2008.

63. Hodgkin AL, Huxley AF. A quantitative description of membrane current and its application to conduction and excitation in nerve. J Physiology 117: 500-544, 1952. doi: 10.1113/jphysiol.1952.sp004764. Precise Neuronal Encoding. PLoS Comput Biol 12: e1004984, 2016. doi: 10.1371/journal.pcbi.1004984.

65. Kobayashi R, Kitano K. Impact of slow K+ currents on spike generation can be described by an

717 66. Monsivais P, Rubel EW. Accommodation enhances depolarizing inhibition in central neurons. J

718 Neurosci 21: 7823-7830, 2001.

719 67. Howard MA, Rubel EW. Dynamic spike thresholds during synaptic integration preserve and enhance 720 temporal response properties in the avian cochlear nucleus. J Neurosci 30: 12063-12074, 2010. doi: 721 10.1523/jneurosci.1840-10.2010. 1997. doi: 10.1016/s0896-6273(00)80388-8. 
724

725

726

727

728

729

730

731

732

733

734

735

736

737

738

739

740

741

742

743

744

745

746

747

748

749

750

751

752

753

754

755

756

757

69. Oertel D, Wright S, Cao X-J, Ferragamo M, Bal R. The multiple functions of T stellate/multipolar/chopper cells in the ventral cochlear nucleus. Hearing Res 276: 61-69, 2011. doi: 10.1016/j.heares.2010.10.018.

70. Rhode WS, Oertel D, Smith PH. Physiological response properties of cells labeled intracellularly with horseradish peroxidase in cat ventral cochlear nucleus. J Comp Neurol 213: 448-463, 1983. doi: 10.1002/cne.902130408.

71. Palmer AR, Wallace MN, Arnott RH, Shackleton TM. Morphology of physiologically characterised ventral cochlear nucleus stellate cells. Exp Brain Res 153: 418-426, 2003. doi: 10.1007/s00221-0031602-6.

72. Xie R, Manis PB. Synaptic transmission at the endbulb of Held deteriorates during age-related hearing loss. J Physiology 595: 919-934, 2017. doi: 10.1113/jp272683.

73. Rhode WS, Greenberg S. Encoding of amplitude modulation in the cochlear nucleus of the cat. J Neurophysiol 71: 1797-1825, 1994. doi: 10.1152/jn.1994.71.5.1797.

74. Frisina RD, Smith RL, Chamberlain SC. Encoding of amplitude modulation in the gerbil cochlear nucleus: II. Possible neural mechanisms. Hearing Res 44: 123-141, 1990. doi: 10.1016/03785955(90)90075-z.

75. Oertel D, Wu SH, Garb MW, Dizack C. Morphology and physiology of cells in slice preparations of the posteroventral cochlear nucleus of mice. J Comp Neurol 295: 136-154, 1990. doi: 10.1002/cne.902950112.

76. Ferragamo MJ, Golding NL, Oertel D. Synaptic inputs to stellate cells in the ventral cochlear nucleus. J Neurophysiol 79: 51-63, 1998. doi: 10.1152/jn.1998.79.1.51.

77. McGinley MJ, Oertel D. Rate thresholds determine the precision of temporal integration in principal cells of the ventral cochlear nucleus. Hearing Res 216-217: 52-63, 2006. doi:

10.1016/j.heares.2006.02.006.

78. Cao X-J, Oertel D. Auditory nerve fibers excite targets through synapses that vary in convergence, strength, and short-term plasticity. J Neurophysiol 104: 2308-2320, 2010. doi: 10.1152/jn.00451.2010.

79. Rothman JS, Manis PB. The roles potassium currents play in regulating the electrical activity of ventral cochlear nucleus neurons. J Neurophysiol 89: 3097-3113, 2003. doi: 10.1152/jn.00127.2002.

80. Rothman JS, Manis PB. Kinetic analyses of three distinct potassium conductances in ventral cochlear nucleus neurons. J Neurophysiol 89: 3083-3096, 2003. doi: 10.1152/jn.00126.2002.

81. Rothman JS, Manis PB. Differential expression of three distinct potassium currents in the ventral cochlear nucleus. J Neurophysiol 89: 3070-3082, 2003. doi: 10.1152/jn.00125.2002.

82. Ngodup T, Romero GE, Trussell LO. Identification of an inhibitory neuron subtype, the L-stellate cell of the cochlear nucleus. Elife 9: e54350, 2020. doi: 10.7554/elife.54350. 
bioRxiv preprint doi: https://doi.org/10.1101/2021.10.08.463546; this version posted October 9, 2021. The copyright holder for this preprint

(which was not certified by peer review) is the author/funder, who has granted bioRxiv a license to display the preprint in perpetuity. It is made available under aCC-BY-NC 4.0 International license.

758 83. Ranjan R, Logette E, Marani M, Herzog M, Tâche V, Scantamburlo E, Buchillier V, Markram H. A 759 Kinetic Map of the Homomeric Voltage-Gated Potassium Channel (Kv) Family. Front Cell Neurosci 13: 760 358, 2019. doi: 10.3389/fncel.2019.00358.

761 